\title{
Comparison of long-term outcomes between Lynch sydrome and sporadic colorectal cancer: a propensity score matching analysis
}

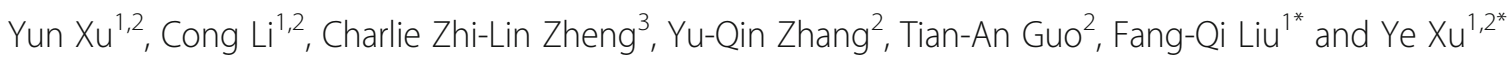

\begin{abstract}
Background: Lynch syndrome (LS) is the most common hereditary colorectal cancer (CRC) syndrome. Comparison of prognosis between LS and sporadic CRC (SCRC) were rare, with conflicting results. This study aimed to compare the long-term outcomes between patients with LS and SCRC.

Methods: Between June 2008 and September 2018, a total of 47 patients were diagnosed with LS by genetic testing at Fudan University Shanghai Cancer Center. A 1:2 propensity score matching was performed to obtain homogeneous cohorts from SCRC group. Thereafter, 94 SCRC patients were enrolled as control group. All of enrolled patients received curative surgeries and standardized postoperative monitoring. The long-term survival rates between the two groups were compared, and the prognostic factors were also analyzed.

Results: The 5-year overall survival rate of LS group was $97.6 \%$, which was significantly higher than of $82.6 \%$ for SCRC group $\left(X^{2}=4.745, p=0.029\right)$. The 5 -year recurrence free survival rate showed no significant differences between the two groups (78.0\% for LS group vs. 70.6\% for SCRC patients; $x^{2}=1.260, p=0.262$ ). The 5-year tumor free survival rates in LS group was $62.1 \%$ for LS patients, which were significantly lower than of $70.6 \%$ for SCRC group $\left(X^{2}=4.258, p=0.039\right)$. Subgroup analysis of recurrent patients show that the LS group had longer overall survival than the SCRC group after combined chemotherapy. By multivariate analysis, we found that tumor recurrence of primary CRC [Risk ratio (95\% (confidence interval): 48.917(9.866-242.539); $p<0.001]$ and late TNM staging [Risk ratio (95\% (confidence interval): 2.968(1.478-5.964); $p=0.002$ ] were independent risk factors for OS.

Conclusion: LS patients have better long-term survival prognosis than SCRC patients, even though the two groups have statistically comparable recurrence free survival. Combined chemotherapy is an effective treatment for LS patients who developed primary CRC recurrence. Standardized postoperative monitoring for LS patients may enable detection of metachronous tumors at earlier stages, which was a guarantee of a favorable prognosis despite lower tumor free survival.
\end{abstract}

Keywords: Colorectal cancer, Lynch syndrome, Mismatch repair, Survival, Chemotherapy

\footnotetext{
* Correspondence: liufa021@163.com; yexu@shmu.edu.cn

'Department of Colorectal Surgery, Fudan University Shanghai Cancer Center, No. 270 Dong-An Road, Shanghai 200032, China

Full list of author information is available at the end of the article
}

(c) The Author(s). 2021 Open Access This article is licensed under a Creative Commons Attribution 4.0 International License, which permits use, sharing, adaptation, distribution and reproduction in any medium or format, as long as you give appropriate credit to the original author(s) and the source, provide a link to the Creative Commons licence, and indicate if changes were made. The images or other third party material in this article are included in the article's Creative Commons licence, unless indicated otherwise in a credit line to the material. If material is not included in the article's Creative Commons licence and your intended use is not permitted by statutory regulation or exceeds the permitted use, you will need to obtain permission directly from the copyright holder. To view a copy of this licence, visit http://creativecommons.org/licenses/by/4.0/. The Creative Commons Public Domain Dedication waiver (http://creativecommons.org/publicdomain/zero/1.0/) applies to the data made available in this article, unless otherwise stated in a credit line to the data. 


\section{Background}

Colorectal cancer (CRC) is one of the most frequently diagnosed malignancies worldwide and the second leading cause of cancer-related death globally [1]. CRC has been recognized as a heterogeneous disease based on different molecular mechanisms, therefore presenting heterogeneous outcomes and drug responses [2-4]. Lynch syndrome (LS) is the most common hereditary CRC syndrome. It results from heterozygous pathogenic germline variants in the mismatch repair (MMR) genes (path_MLH1, path_MSH2, path_MSH6, and path_ PMS2), accounting for approximately $3-5 \%$ of all cases of CRC $[5,6]$. In addition to higher risk for CRC, LS presents significantly higher risks for cancers in organs including the endometrium, ovaries, stomach, small bowel, bile duct, pancreas and upper urinary tract $[5,6]$. The consequent tumors present the phenotypes of MMR protein deficiency (dMMR) under immunohistochemistry (IHC) and microsatellite instability (MSI).

During the last decade, multi-gene cancer panel tests on suspected LS patients have allowed the identification of LS at an increasing rate. Correspondingly, the introduction of tailored policies of management and treatment, different from those for sporadic colorectal cancer (SCRC), has largely contributed to the long-term prognosis of LS patients and their affected relatives.

In theory, CRC with dMMR should have better prognosis and therapeutic responses because the MMR pathway is involved in triggering cell death after chemotherapy-induced DNA damage [4, 7-10]. Although analysis of LS patients' survival prognoses has been reported by several western studies [7-17], few studies compared the long-term prognoses of LS with that of SCRC, and those that did had conflicting results. In addition, almost all previous findings on LS were derived from Western medical centers, and data from Asian populations remain lacking.

The aim of this study is to compare the long-term survival outcome of LS associated CRC patients with that of SCRC patients. A propensity score matching (PSM) analysis was used to balance the baseline of the two groups. Afterwards, overall survival (OS), recurrence free survival (RFS), and tumor free survival (TFS) were compared, and prognostic factors associated with survival were also analyzed. To our knowledge, the current article is the first report on survival of LS from one of the largest colorectal surgery centers in China, and thus may better inform the comprehensive understanding of LS and clarify the differences between LS and SCRC.

\section{Methods}

\section{Patients}

Between June 2008 and September 2018, a total of 22, 833 consecutive CRC patients underwent curative surgeries, depending on the location of tumors, at the Fudan University Shanghai Cancer Centre.

As in our clinical routine, patients who met at least one of the following two criteria were defined as suspected LS patients: 1) dMMR positive under IHC; 2) family history fulfills clinical criteria, including the Amsterdam criteria [18] and Bethesda guidelines [19]. Multi-gene panel testing that included 139 genes was recommended for suspected LS patients and some of their affected relatives. All patients gave informed consent for genetic analyses. Germline variants were defined as variants carried by both patients and their respective family members, for whom genetic counseling was recommended. Of the 252 suspected LS patients that underwent genetic testing, 47 were identified as carrying a pathogenic variant (PV) in MMR genes. They were diagnosed with LS and classified as LS group. SCRC was defined as patients with neither family history nor dMMR phenotype. Based on the baseline of LS group, we matched 94 SCRC patients (1:2) as SCRC group by propensity score matching.

\section{Immunohistochemistry}

IHC were performed for all patients who underwent curative surgeries. MMR deficiency was determined according to the absence of protein expression for any one of several genes including $h M L H 1, h M S H 2, h M S H 6$, and hPMS2. IHC was performed using the fully automated BenchMark ULTRA platform (Ventana Medical Systems, Inc., Tucson, AZ, United States). Normal tissues adjacent to the tumor or lymphocytes in the stroma served as internal positive controls. Each result was confirmed by at least two experienced pathologists.

\section{Mutation screening of KRAS, NRAS and BRAF}

Mutation screening of KRAS, NRAS and BRAF were performed for all patients who underwent curative surgeries. The methods of mutation detection in KRAS, NRAS and $B R A F$ were the same as our previous report [20]. All results were confirmed according to the criterion suggested by the manufacturer.

\section{Next-generation sequencing}

Peripheral blood $(10 \mathrm{~mL})$ was collected, stored in ethylenediaminetetraacetic acid tubes, and allowed to stand at $25^{\circ} \mathrm{C}$ for $2 \mathrm{~h}$. The supernatant was transferred to a $15-\mathrm{mL}$ centrifuge tube and then centrifuged for $10 \mathrm{~min}$ at $2200 \mathrm{~g}$ at $4{ }^{\circ} \mathrm{C}$. Thereafter, the intermediate white blood cells were transferred to a $1.5-\mathrm{ml}$ centrifuge tube. The DNA was recovered using the MagPure FFPE DNA LQ Kit (Magen). NGS was conducted on the germline DNA as a standard genetic testing for germline analysis.

Sequence data were mapped to the reference human genome (hg19) using BWA aligner 0.7.10. Local 
alignment optimization was performed using GATK 3.2. Germline SNVs were identified using Varscan with default parameters. Germline indels were identified using Varscan and GATK. Pathogenic variants were determined by a clinical molecular geneticist according to the guidelines of the American College of Medical Genetics [21]. The ClinVar (https://www.ncbi.nlm.nih.gov/clinvar/) was used during manual curation for final confirmation of the results. The InSIGHT database (https://www.insightgroup.org/variants/databases/) was used for the pathogenicity classification of the MMR genes.

\section{Clinical data acquisition and follow-up evaluation}

For the 141 enrolled patients, the baseline information on tumor characteristics, pathological results, and treatment were retrospectively obtained from medical charts. Follow-ups conducted for LS patients were according to clinical practice guidelines [22], and regular follow-ups were performed for SCRC patients. For all patients, contrast-enhanced abdominal CT/MRI and carcinoembryonic antigen (CEA) test were performed every 2-3 months within the first 1 year after surgery and every 46 months thereafter, to monitor tumor recurrence. Chest radiography was taken annually to detect lung metastasis. Colonoscopy was performed 1 year after surgery for all patients, then annually for LS patients and every $2-3$ years for SCRC patients. For female LS patients, routine follow-ups also included annual gastroscopy, breast ultrasonography and gynecological examination. During the follow-up evaluations, any occurrence of tumor recurrence of primary $\mathrm{CRC}$, metachronous $\mathrm{CRC}$, and extra-colonic cancer was recorded.

Tumor recurrence was defined as any recurrent tumor at the anastomotic site, invasion of adjacent tissues, lymph node metastasis, or distant metastasis that developed within 5 years after surgery. Synchronous tumors were defined as two colorectal tumors that were discovered simultaneously or within 6 months of each other, and the metachronous colorectal tumors were discovered more than 6 months apart [23]. For patients with synchronous tumors, the tumor with the higher stage was documented as the primary tumor [17]. Extracolonic cancers were defined as primary cancers within the disease spectrum of LS and presenting dMMR under IHC. This study was censored on July 31, 2020. The mean follow-up period was $(80.3 \pm 41.2)$ months for SCRC patients and $(82.0 \pm 57.2)$ months for LS patients, no significant difference was observed between the two groups in follow-up period $\left(x^{2}=0.238, p=0.626\right)$.

\section{Analysis of outcome}

The outcomes of this analysis were oncologic outcomes including OS, RFS, and TFS. OS time was defined as the period between the date of surgery to the date of death or last follow-up. RFS time was defined as the period between the date of surgery and the date of tumor recurrence or last follow-up. TFS time was defined as the period between the date of surgery and the date of tumor recurrence, metachronous CRC, extra-colonic cancer or last follow-up. Treatment options involving repeat resection, chemotherapy, radiotherapy, immunotherapy, conservative treatment for these events were formulated based on the recommendations of our multidisciplinary team. The primary endpoint was the 5-year OS rate; the secondary endpoints were 5-year TFS and RFS rates.

\section{Statistical analysis}

All analyses were performed using the R software package (version 3.0.2; R Foundation for Statistical Computing, Vienna, Austria) and SPSS (statistical software (version 20.0; Chicago, Ill).

Propensity score matching analysis was performed using the $\mathrm{R}$ software package. We used propensity score matching to balance the assignment of the included patients. Patients were matched using the following baseline characteristics as covariates: age, gender, CEA, tumor location, tumor size, pathologic result (classification, differentiation grade, cancerous node, vascular invasion, perineural invasion), TNM stage, KRAS (wild type vs. variant type), NRAS (wild type vs. variant type), adjuvant chemotherapy (received or not) (Table 1). Each variable was multiplied by a coefficient that was calculated using logistic regression analysis, and the sum of these values was taken as the propensity score for individual patients. For matching, complex LS and SCRC pairs with an equivalent propensity score were selected by a 1: 2 matching. Thereafter, we matched 47 LS patients with 94 SCRC patients using the nearest neighbor method (caliber $=0.02)$.

We assessed the balance of all baseline covariates in Table 1 between the two groups after propensity score matching. Continuous variables were compared using the Student $t$ test between the two groups. Categorical variables were compared using the Chi square test or Fisher's exact test. OS, TFS, and RFS curves were evaluated using Kaplan-Meier curves and compared using the log-rank test. Variables with $p$-values less than 0.05 in the univariate analysis were entered into a Cox proportional hazards model for multivariate analysis. For all statistical tests, two-tailed p-values less than 0.05 were considered statistically significant.

\section{Results}

Molecular characteristics

In the LS group, PVs of $M L H 1$ were identified in 17 (36.2\%) probands and those of MSH2, MSH6, and PMS2 were identified in 18 (38.3\%), $10(21.3 \%)$, and $2(4.2 \%)$ 
Table 1 Demographic and clinical characteristics of 141 colorectal cancer patients

\begin{tabular}{|c|c|c|c|c|}
\hline Variables & $\begin{array}{l}\text { LS group } \\
(N=47)\end{array}$ & $\begin{array}{l}\text { SCRC group } \\
(N=94)\end{array}$ & $\mathrm{x}^{2}$ value & $p$ value \\
\hline Age (years) & & & 0.070 & 0.792 \\
\hline$<50$ & $35(74.5 \%)$ & $68(72.3 \%)$ & & \\
\hline$\geq 50$ & $12(2.5 .5 \%)$ & $26(27.7)$ & & \\
\hline Gender & & & 0.058 & 0.810 \\
\hline Male & $26(55.3 \%)$ & $54(57.4 \%)$ & & \\
\hline Female & $21(44.7 \%)$ & $40(42.6 \%)$ & & \\
\hline CEA (ng/ml) & & & 0.104 & 0.747 \\
\hline$\geq 5.2$ & $7(14.9 \%)$ & $16(17.0 \%)$ & & \\
\hline$<5.2$ & $40(85.1 \%)$ & $78(83.0 \%)$ & & \\
\hline Location & & & 3.177 & 0.365 \\
\hline Right colon & 18(38.3\%) & $40(42.6 \%)$ & & \\
\hline Left colon & $20(42.6 \%)$ & $41(43.6 \%)$ & & \\
\hline Rectal & $5(10.6 \%)$ & $11(11.7 \%)$ & & \\
\hline Multiple & $4(8.5 \%)$ & $2(2.1 \%)$ & & \\
\hline Tumor size $^{\mathrm{a}}(\mathrm{cm})$ & $5.17 \pm 2.61$ & $5.21 \pm 2.79$ & 0.106 & 0.754 \\
\hline Pathological classification & & & 0.474 & 0.789 \\
\hline Adenocarcinoma & $34(72.3 \%)$ & $71(75.5 \%)$ & & \\
\hline Partial mucinous & $5(10.7 \%)$ & $11(11.7 \%)$ & & \\
\hline Mucinous adenocarcinoma & $8(17.0 \%)$ & $12(12.8 \%)$ & & \\
\hline Differentiation grade & & & 0.259 & 0.878 \\
\hline Well & $1(2.1 \%)$ & $1(1.1 \%)$ & & \\
\hline Moderately & $28(59.6 \%)$ & $56(59.5 \%)$ & & \\
\hline Poorly & 18(38.3\%) & $37(39.4 \%)$ & & \\
\hline Cancerous node & & & 0.534 & 0.465 \\
\hline Occurrence & $2(4.3 \%)$ & $7(7.4 \%)$ & & \\
\hline Absence & 45(95.7\%) & $87(92.6 \%)$ & & \\
\hline Vascular invasion & & & 0.534 & 0.461 \\
\hline Occurrence & $8(17.0 \%)$ & $21(22.3 \%)$ & & \\
\hline Absence & 39(83.0\%) & 73(77.7\%) & & \\
\hline Perineural invasion & & & 0.252 & 0.616 \\
\hline Occurrence & $6(12.8 \%)$ & $15(16.0 \%)$ & & \\
\hline Absence & $41(87.2 \%)$ & $79(84.0 \%)$ & & \\
\hline T stage & & & 0.130 & 0.937 \\
\hline $\mathrm{T} 1$ & $7(14.9 \%)$ & $12(12.8 \%)$ & & \\
\hline $\mathrm{T} 2$ & $8(17.0 \%)$ & 17(18.1\%) & & \\
\hline T3 & $32(68.1 \%)$ & $65(69.1 \%)$ & & \\
\hline N stage & & & 1.840 & 0.399 \\
\hline No & $34(72.3 \%)$ & $57(60.6 \%)$ & & \\
\hline N1 & $9(19.1 \%)$ & $23(24.5 \%)$ & & \\
\hline N2 & $4(8.6 \%)$ & $14(14.9 \%)$ & & \\
\hline Metastasis & & & 0.265 & 0.607 \\
\hline Occurrence & $2(4.3 \%)$ & $6(6.4 \%)$ & & \\
\hline Absence & $45(95.7 \%)$ & $88(93.6 \%)$ & & \\
\hline
\end{tabular}


Table 1 Demographic and clinical characteristics of 141 colorectal cancer patients (Continued)

\begin{tabular}{llll}
\hline Variables & $\begin{array}{l}\text { LS group } \\
(\mathbf{N = 4 7 )}\end{array}$ & $\begin{array}{l}\text { SCRC group } \\
(\boldsymbol{N}=\mathbf{9 4})\end{array}$ & $\mathbf{X}^{\mathbf{2} \text { value }}$ \\
\hline TNM stage & & & 1.200 \\
I & $13(27.7 \%)$ & $27(28.7 \%)$ & \\
II & $17(36.2 \%)$ & $30(31.9 \%)$ & \\
III & $15(31.8 \%)$ & $31(33.0 \%)$ & \\
IV & $2(4.3 \%)$ & $6(6.4 \%)$ & 0.695 \\
KRAS mutant & $21(44.6 \%)$ & $49(52.1 \%)$ & 0.104 \\
NRAS mutant & $2(4.3 \%)$ & $3(3.2 \%)$ & 1.420 \\
Adjuvant chemotherapy & & & 0.704 \\
Received & $26(55.3 \%)$ & $42(44.7 \%)$ & 0.233 \\
\hline
\end{tabular}

CEA Carcinoembryonic antigen, LS Lynch syndrome, SCRC Sporadic colorectal cancer

probands, respectively. Variants from LS patients and frequency of each variant in the Asian population are summarized in Table 2. In patients identified with PVs in MMR genes, the results of IHC MMR staining were consistent with those of gene detection.

\section{Patient groups}

After propensity score 1:2 matching analysis, 94 SCRC patients were enrolled as control group. The baseline characteristics of these two groups were compared and summarized in the Table 1, and no significant difference was found between the two groups in any variables. In the LS group, synchronous CRC were observed in four $(4 / 47,8.5 \%)$ patients. However, the occurrence of synchronous tumors is a major clinical feature intrinsic to LS and is rarely observed in SCRC patients. Thus, this variable did not serve as a baseline for comparison.

\section{Recurrence of primary CRC and recurrence free survival}

During the follow up, a total of 26 (27.7\%) SCRC patients developed tumor recurrence including 14 (14.9\%) of liver metastases, 4 (4.3\%) abdominal lymph node metastasis, 3 (3.2\%) of lung metastases, 3 (3.2\%) of invasion of adjacent tissues, and 2 (2.1\%) of extensive metastasis. In LS group, 9 (19.1\%) patients developed tumor recurrence including 4 (8.5\%) of liver metastases, 2 of $(4.3 \%)$ of invasion of adjacent tissues, and 2 (4.3\%) of abdominal lymph node metastasis. No significant differences were observed between the two groups $\left(\mathrm{X}^{2}=1.216, p=\right.$ $0.270)$. The average RFS period was $(110.8 \pm 61.8)$ months [95\% confidence interval (CI): 98.3-123.3] for SCRC group and $(177.3 \pm 85.9)$ months (95\% CI: $152.8-$ 201.9) for LS group. The 1-, 3-, and 5-year RFS rates for the SCRC group were $85.1,77.6$, and $70.6 \%$, respectively, whereas those for the LS group were 95.7, 86.9, and $78.0 \%$, respectively. No significant differences were observed between the two groups in RFS $\left(X^{2}=1.260, p=\right.$ 0.262, Fig. 1a).
All patients who developed tumor recurrence in both groups received 5-fluorouracil based chemotherapy (XELOX or mFOLFOX6). In LS group, all patients received targeted agents, including cetuximab for 3 patients with wild-type KRAS and bevacizumab for 6 patients with variant-type KRAS. In SCRC group, cetuximab combined with chemotherapy was performed for 4 patients with wild-type KRAS and bevacizumab for 7 patients with variant-type KRAS.

\section{Metachronous tumor and tumor free survival}

During the follow-up period, $34.0 \%(16 / 47)$ of the patients in the LS group developed metachronous CRC, with average period of $(28.78 \pm 29.14)$ months between the occurrence of primary and metachronous CRC. In addition, 11 patients developed 15 cases of primary extra-colonic cancer, including 5 cases of endometrial cancer, 5 cases of gastric cancer, 2 cases of small intestinal cancer, and 1 case each of ovarian, breast, and cutaneous cancer. Therefore, the average TFS period was (82.4 \pm 78.7$)$ months (95\% CI: 59.9-104.9) for LS group and (107.7 \pm 63.1$)$ months (95\% CI: 94.9-120.5) for SCRC group. In LS group, the 1-, 3-, and 5-year TFS rates were $89.4,71.5$, and $62.1 \%$ respectively, which were significantly lower than those in SCRC group (85.1, 77.6, and $70.6 \%$, respectively; $\mathrm{X}^{2}=4.258, p=0.039$ ) (Fig. 1b).

All patients with metachronous cancers received radical resection. Of the 16 patients who developed metachronous CRC, 14 patients underwent extended resection, including 9 cases of subtotal colectomy, 4 of extended left hemicolectomy, 1 of total colectomy, and 1 of extended right hemicolectomy; the other 2 patients underwent standard radical resection. 5-fluorouracil based adjuvant chemotherapy was performed for $2 \mathrm{pa}$ tients in stage II and 5 patients in stage III.

\section{Overall survival}

During the follow-up period, 4 (8.5\%) LS patients, including $2 M L H 1$ variants carriers and $2 \mathrm{MSH} 2$ variants 
Table 2 Variants in the LS patients and frequency of each variant in Asian population

\begin{tabular}{|c|c|c|c|}
\hline Gene & Variants (HGVS) & Clinical Significance & Frequency \\
\hline MLH1 & NM_001167618.2(MLH1):c.-33del(p.lle231fs) & Pathogenic & No data \\
\hline MLH1 & NM_000249.3(MLH1):c.1976G>C (p.Arg659Pro) & Pathogenic & 0.00002 \\
\hline MLH1 & NM_000249.3(MLH1):c.883A>G (p.Ser295G/y) & Pathogenic & No data \\
\hline MLH1 & NM_000249.4(MLH1):C.244A>G (p.Thr82Ala) & Likely pathogenic & 0.00000 \\
\hline MLH1 & NM_000249.3(MLH1):c.979C>T (p.Gln327Ter) & Pathogenic & 0.0000 \\
\hline MLH1 & NM_000249.3(MLH1):c.1489_1490insCG(p.Arg497fs) & Pathogenic & No data \\
\hline MLH1 & NM_000249.3(MLH1):C.199G>C (p.Gly67Arg) & Pathogenic & 0.0000 \\
\hline MLH1 & NM_000249.3(MLH1):C.2101C>A (p.Gln701Lys) & Likely pathogenic & 0.00249 \\
\hline MLH1 & NM_001167618.2(MLH1):c.-131_-130GA(p.Glu199fs) & Pathogenic & No data \\
\hline MLH1 & NM_000249.3(MLH1):c.116+1G>A(5 prime UTR) & Likely pathogenic & No data \\
\hline MLH1 & NM_000249.3(MLH1):C.1990-2A>G & Pathogenic & No data \\
\hline MLH1 & NM_000249.3(MLH1):C.453+1G>T & Likely pathogenic & No data \\
\hline MLH1 & NM_000249.3(MLH1):C.250A>G (p.Lys84G/u) & Likely pathogenic & No data \\
\hline MSH2 & NM_000251.3(MSH2):c.1165C>T (p.Arg389Ter) & Pathogenic & No data \\
\hline MSH2 & NM_000251.2(MSH2):c.244A>T (p.Lys82Ter) & Pathogenic & No data \\
\hline MSH2 & NM_000251.2(MSH2):c.877A>G (p.Thr293Ala) & Likely pathogenic & 0.0000 \\
\hline MSH2 & NM_000251.3(MSH2):c.2038C >T (p.Arg680Ter) & Pathogenic & 0.0000 \\
\hline MSH2 & NM_000251.2(MSH2):c.1528C>T (p.GIn510Ter) & Pathogenic & No data \\
\hline MSH2 & NM_000251.2(MSH2):c.1963G>A (p.Val655lle) & Likely pathogenic & 0.00012 \\
\hline MSH2 & NM_000251.2(MSH2):C.859G>T (p.Gly287Ter) & Pathogenic & No data \\
\hline MSH2 & NM_000251.2(MSH2):c.1077A>T (p.Arg359Ser) & Pathogenic & No data \\
\hline MSH2 & NM_000251.3(MSH2):c.1710 T>G (p.Tyr570Ter) & Pathogenic & No data \\
\hline MSH2 & NM_000251.2(MSH2):c.352dup (p.Tyr118fs) & Pathogenic & No data \\
\hline MSH2 & NM_000251.2(MSH2):c.1009C>T (p.Gln337Ter) & Pathogenic & No data \\
\hline MSH2 & NM_000251.3(MSH2):c.2131C>T (p.Arg711Ter) & Pathogenic & 0.0000 \\
\hline MSH2 & NM_000251.2(MSH2):c.1042C>T (p.Gln348Ter) & Pathogenic & No data \\
\hline MSH2 & NM_000251.2(MSH2):c.2021G>A (p.Gly674Asp) & Likely pathogenic & No data \\
\hline MSH6 & NM_000179.2(MSH6):c.3252dup (p.Thr1085fs) & Pathogenic & No data \\
\hline MSH6 & NM_000179.2(MSH6):c.718C>T (p.Arg240Ter) & Pathogenic & 0.0000 \\
\hline MSH6 & NM_000179.2(MSH6):c.2294dup (p.Cys765fs) & Pathogenic & No data \\
\hline MSH6 & NM_000179.2(MSH6):c.3515G>C (p.Arg1172Thr) & Pathogenic & No data \\
\hline MSH6 & NM_000179.3(MSH6):c.3202C>T (p.Arg1068*) & Pathogenic & No data \\
\hline MSH6 & NM_000179.2(MSH6):c.652A>T (p.Lys218Ter) & Pathogenic & 0.00000 \\
\hline MSH6 & NM_000251.2(MSH2):c.518 T>C (p.Leu173Pro) & Likely pathogenic & No data \\
\hline PMS2 & large intragenic in EXON9 & Pathogenic & No data \\
\hline PMS2 & NM_000535.7:c.2 T>G(p.Met1Arg) & Pathogenic & 0.000 \\
\hline
\end{tabular}

LS Lynch syndrome

carrier, died of tumor recurrence. No significant differences in OS were found among the four genotypes $\left(x^{2}=\right.$ $3.803 p=0.430)$. In SCRC group, $24(25.5 \%)$ SCRC patients died of tumor recurrence.

The average OS period was (188.4 \pm 96.3$)$ months $(95 \%$ CI: 160.9-216.0) for LS group and (113.8 \pm 58.4$)$ months (95\% CI: 102.0-126.6) for SCRC group. For LS patients, the 1-, 3-, and 5-year OS rates were 100.0, 97.6, and
97.6\%, respectively, which were significantly higher than those of SCRC patients $(95.7,88.3$, and $82.6 \%$, respectively; $\chi^{2}=4.745 ; p=0.029$ ) (Fig. 2).

\section{Prognostic factor analysis for OS and RFS}

Univariate analysis showed that sex, etiology, pathological classification, cancerous node, vascular invasion, perineural invasion, TNM stage, and tumor recurrence 

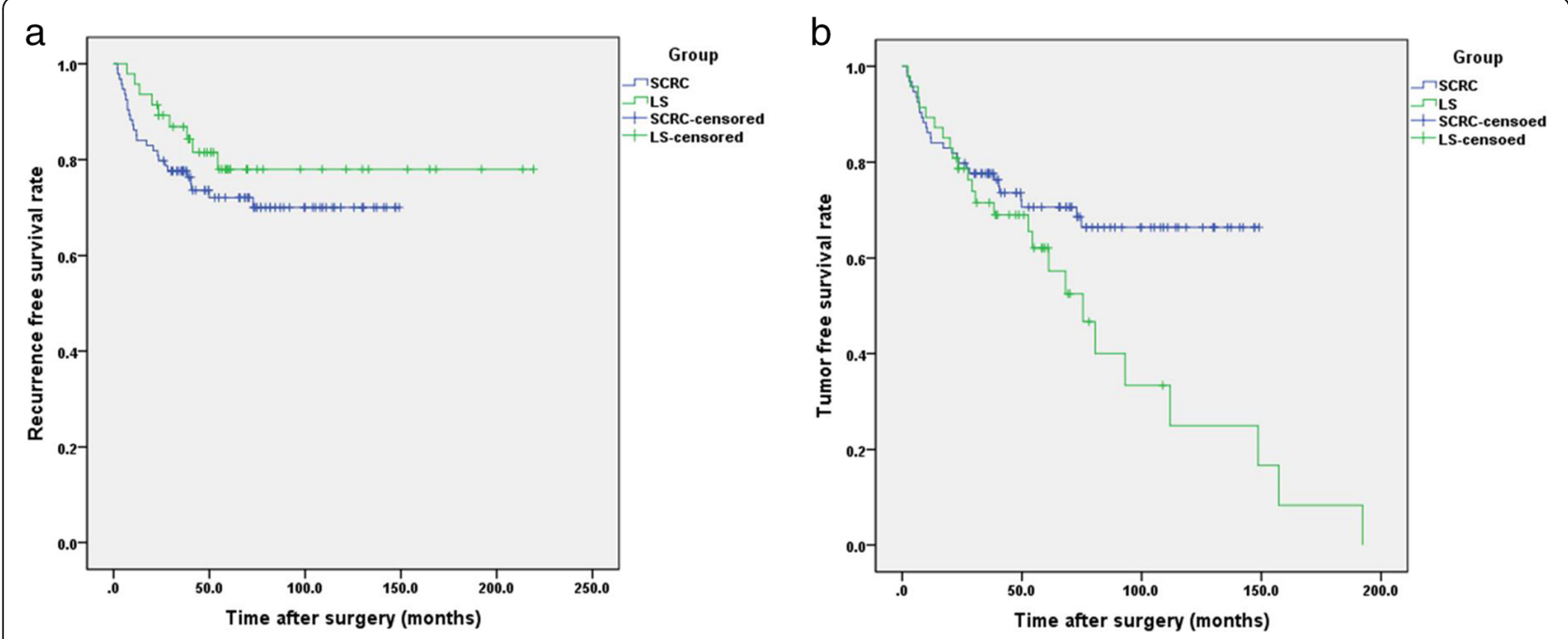

Fig. 1 Recurrence free survival curves (a) and tumor free survival curves (b) for patients in LS group and SCRC group. Survivals were evaluated using Kaplan-Meier curves and compared with the log-rank test

of primary CRC were significantly associated with OS. Multivariate analysis showed that etiology (LS vs. SCRC), TNM stage, and tumor recurrence primary CRC were independent prognostic factors in OS (Table 3). In addition, univariate analysis showed that pathological classification, differentiation grade, cancerous node, vascular invasion, perineural invasion, and TNM stage were significantly associated with RFS. Multivariate analysis showed that cancerous node, vascular invasion, and
TNM stage were the independent prognostic factors in RFS (Table 4).

\section{Subgroup survival}

For early-onset ( $<50$ years) CRC patients, the $1-, 3-$, and 5 -year OS rates for LS group were 100, 96.8, and 96.8\%, respectively, whereas those for the SCRC group were 95.6, 89.7, and 82.0\%, respectively. No significant

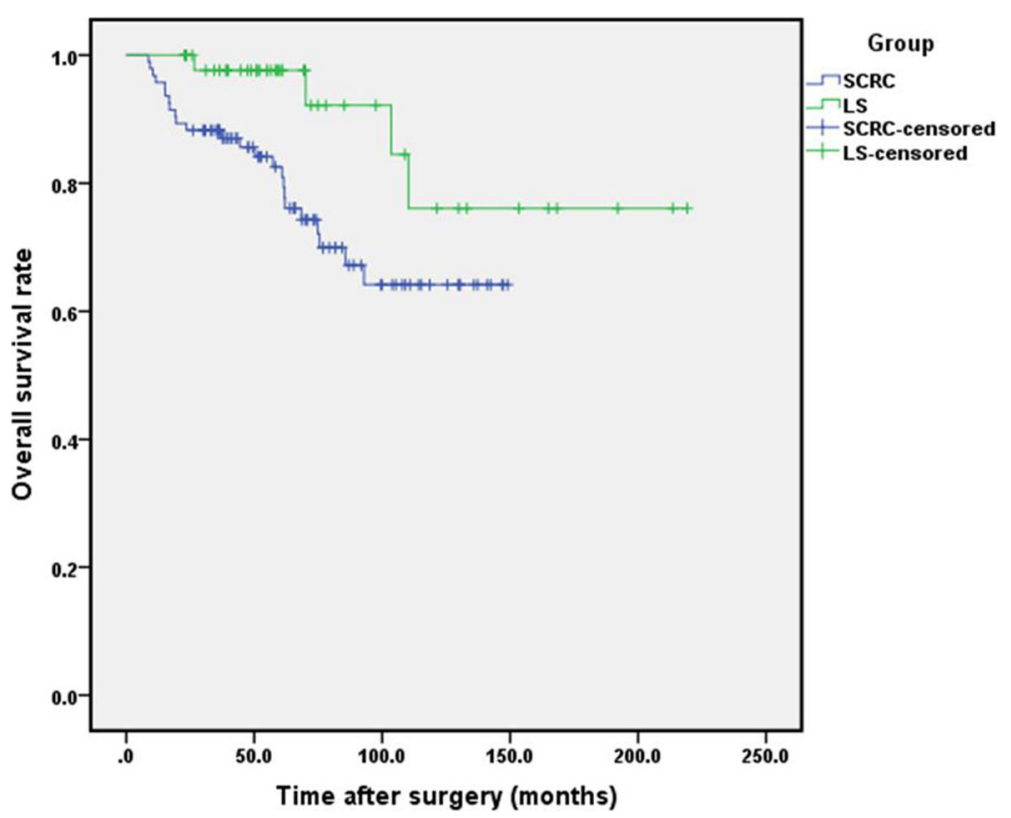

Fig. 2 Overall survival curves for patients in LS group and SCRC group. Survivals were evaluated using Kaplan-Meier curves and compared with the log-rank test 
Table 3 Factors associated with overall survival in the patients of LS and SCRC group (univariate and multivariate analysis)

\begin{tabular}{|c|c|c|c|c|c|c|}
\hline \multirow{2}{*}{$\begin{array}{l}\text { Variable } \\
\text { Total }\end{array}$} & \multirow{2}{*}{$\begin{array}{l}\text { N. patients } \\
141\end{array}$} & \multirow{2}{*}{$\begin{array}{l}\text { N. events }{ }^{a} \\
28\end{array}$} & \multicolumn{2}{|c|}{ Univariate analysis } & \multicolumn{2}{|l|}{ Multivariate analysis } \\
\hline & & & $\mathrm{x}^{2}$ & $p$ value & Risk ratio $(95 \% \mathrm{Cl})$ & $p$ value \\
\hline Sex & & & 4.745 & 0.028 & $1.360(0.525-0.770)$ & 0.527 \\
\hline Male & 80 & 24 & & & & \\
\hline Female & 61 & 4 & & & & \\
\hline Age & & & 0.022 & 0.883 & & \\
\hline$<50$ & 103 & 21 & & & & \\
\hline$\geq 50$ & 38 & 7 & & & & \\
\hline CEA & & & 0.482 & 0.488 & & \\
\hline$<5.2$ & 118 & 21 & & & & \\
\hline$\geq 5.2$ & 23 & 7 & & & & \\
\hline Etiology & & & 4.745 & 0.029 & $0.106(0.025-0.446)$ & 0.002 \\
\hline Lynch syndrome & 47 & 4 & & & & \\
\hline Sporadic CRC & 94 & 24 & & & & \\
\hline Location & & & 3.235 & 0.357 & & \\
\hline Right colon & 58 & 8 & & & & \\
\hline Left colon & 61 & 14 & & & & \\
\hline Rectal & 16 & 3 & & & & \\
\hline Multiple & 6 & 3 & & & & \\
\hline Pathological classification & & & 11.122 & 0.004 & $1.504(0.770-2.937)$ & 0.233 \\
\hline Adenocarcinoma & 105 & 21 & & & & \\
\hline Partial mucinous & 16 & 0 & & & & \\
\hline Mucinous adenocarcinoma & 20 & 7 & & & & \\
\hline Differentiation grade & & & 2.611 & 0.271 & & \\
\hline Well & 2 & 0 & & & & \\
\hline Moderately & 84 & 15 & & & & \\
\hline Poorly & 55 & 13 & & & & \\
\hline Cancerous node & & & 13.123 & $<0.001$ & $3.285(0.860-12.546)$ & 0.082 \\
\hline Occurrence & 9 & 5 & & & & \\
\hline Absence & 132 & 23 & & & & \\
\hline Vascular invasion & & & 10.163 & 0.001 & $3.404(0.915-12.662)$ & 0.068 \\
\hline Occurrence & 112 & 17 & & & & \\
\hline Absence & 29 & 11 & & & & \\
\hline Perineural invasion & & & 41.204 & $<0.001$ & $0.707(0.247-2.028)$ & 0.519 \\
\hline Occurrence & 21 & 13 & & & & \\
\hline Absence & 120 & 15 & & & & \\
\hline TNM stage & & & 57.546 & $<0.001$ & $2.968(1.478-5.964)$ & 0.002 \\
\hline 1 & 40 & 2 & & & & \\
\hline$\|$ & 47 & 4 & & & & \\
\hline III & 46 & 16 & & & & \\
\hline IV & 8 & 6 & & & & \\
\hline KRAS & & & 0.225 & 0.636 & & \\
\hline Wild type & 71 & 9 & & & & \\
\hline Variant type & 70 & 19 & & & & \\
\hline NRAS & & & 0.011 & 0.916 & & \\
\hline
\end{tabular}


Table 3 Factors associated with overall survival in the patients of LS and SCRC group (univariate and multivariate analysis) (Continued)

\begin{tabular}{|c|c|c|c|c|c|c|}
\hline \multirow{2}{*}{$\begin{array}{l}\text { Variable } \\
\text { Total }\end{array}$} & \multirow{2}{*}{$\begin{array}{l}\text { N. patients } \\
141\end{array}$} & \multirow{2}{*}{$\begin{array}{l}\text { N. events }{ }^{a} \\
28\end{array}$} & \multicolumn{2}{|c|}{ Univariate analysis } & \multicolumn{2}{|l|}{ Multivariate analysis } \\
\hline & & & $\mathrm{x}^{2}$ & $p$ value & Risk ratio $(95 \% \mathrm{Cl})$ & $p$ value \\
\hline Wild type & 136 & 27 & & & & \\
\hline Variant type & 5 & 1 & & & & \\
\hline Recurrence of primary CRC & & & 106.81 & $<0.001$ & 48.917(9.866-242.539) & $<0.001$ \\
\hline Occurrence & 35 & 25 & & & & \\
\hline Absence & 106 & 3 & & & & \\
\hline
\end{tabular}

CEA Carcinoembryonic antigen, LS Lynch syndrome, SCRC Sporadic colorectal cancer, N. Number, Cl Confidence interval, CRC Colorectal cancer ${ }^{a}$ Events refers to death

differences were observed between the two subgroups $\left(\chi^{2}=3.332, p=0.068\right)$ (Fig. 3a).

For patients who develop tumor recurrence, the 1-, 3-, and 5-year OS rates for LS patients were 100.0, 88.9, and $88.9 \%$, respectively, which were significantly higher than those of SCRC patients (84.6, 57.7, and 39.1\%, respectively; $\mathrm{X}^{2}=9.354 ; p=\mathrm{c} 0.002$ ) (Fig. 3b).

\section{Discussion}

Hereditary background and molecular subtypes are significant factors in the prognosis of CRC patients [24]. As the most common hereditary CRC, LS is characterized by earlier onset, poorly differentiated tumors, and mucinous differentiation [25]. Those clinicopathologic features different from SCRC made it difficult to compare the long-term prognoses between those two subgroups. Using propensity score matching analysis, with the clinical characteristics of LS as baseline and a 1:2 matching ratio between LS and SCRC patients, we achieved comparability between the two groups in the current study. We found that OS period in LS patients was significantly longer than in SCRC patients, which may indicate that long-term prognosis for LS patients is better than that of SCRC patients. We used tumor recurrence of primary CRC to calculate RFS and included metachronous tumor occurrence into the calculations for TFS, because although LS patients have higher metachronous tumor occurrence rates, the occurrence of such second primary tumors is different from primary tumor recurrence in clinical significance. We found that RFS for LS patients is comparable to that for SCRC group, whereas the high proportion of metachronous CRCs and extra-colonic cancers in LS group have remarkably shortened TFS time, resulting in higher TFS rates for the SCRC group.

By analyzing genetic testing, we found that the Chinese population's LS genotype distribution is similar to distributions reported in western review [6], with $M L H 1$ and $M S H 2$ being the majority. However, due to insufficient sample size, no significant differences in the phenotypes and long-term prognosis of each genotype can be found. LS remains underdiagnosed and genetic counseling of LS in the Chinese population is also insufficient. Therefore, prospective studies with larger samples are needed to explore the genotypes and phenotypes of Asian LS patients would also improve screening and follow-up policies for Asian patients.

While comparing primary tumor recurrence rate, previous studies demostrated that LS patients have lower risk of tumor recurrence [26, 27]. However, in the current study, the LS and SCRC groups show no statistical difference in RFS, despite showing a significant tendency of dispersion in their RFS survival curves. A possible reason is that because the majority of tumors in both groups are at early stage. As a result, our follow-up time is not long enough to yield statistical difference in comparison of RFS.

A higher probability of metachronous CRC and extracolonic tumor is the most prominent feature of LS [6]. In the current study, metachronous CRC and extracolonic tumors were present in a large portion of LS patients, which significantly shortened the LS group's TFS. Standardized postoperative monitoring enabled us to detect these metachronous tumors at earlier stages. All patients with second primary tumor occurrence received radical resections and individualized adjuvant treatments, including chemotherapy, targeted therapy, etc., according to each patient's condition. The longer OS and better prognoses of our LS patients, despite their shorter TFS, may be the result of the above strategy. In fact, research shows that metachronous tumor occurrence should have no significant impact on OS if it can be cured through resection [28]. Our result affirms this phenomenon and highlights the importance of standardized postoperative monitoring for early detection and proper treatment.

The current study confirms what many studies have already proposed, that LS patients have better long-term prognosis than SCRC patients [10-17]. LS-associated tumors may be associated with better prognoses and therapeutic responses, in part because the DNA MMR system, which is missing in CRCs with MSI, is involved in triggering cell death after chemotherapy-induced 
Table 4 Factors associated with recurrence free survival in the patients of LS and SCRC group (univariate and multivariate analysis)

\begin{tabular}{|c|c|c|c|c|c|c|}
\hline \multirow{2}{*}{$\begin{array}{l}\text { Variable } \\
\text { Total }\end{array}$} & \multirow{2}{*}{$\begin{array}{l}\text { N. patients } \\
141\end{array}$} & \multirow{2}{*}{$\begin{array}{l}\text { N. events }{ }^{a} \\
35\end{array}$} & \multicolumn{2}{|c|}{ Univariate analysis } & \multicolumn{2}{|l|}{ Multivariate analysis } \\
\hline & & & $\mathrm{x}^{2}$ & $p$ value & Risk ratio $(95 \% \mathrm{Cl})$ & $p$ value \\
\hline Sex & & & 1.173 & 0.314 & & \\
\hline Male & 80 & 21 & & & & \\
\hline Female & 61 & 14 & & & & \\
\hline \multicolumn{7}{|l|}{ Age } \\
\hline$<50$ & 103 & 26 & 0.092 & 0.762 & & \\
\hline$\geq 50$ & 38 & 9 & & & & \\
\hline CEA & & & 0.220 & 0.639 & & \\
\hline$<5.2$ & 118 & 28 & & & & \\
\hline$\geq 5.2$ & 23 & 7 & & & & \\
\hline Etiology & & & 1.260 & 0.262 & & \\
\hline Lynch syndrome & 47 & 9 & & & & \\
\hline Sporadic CRC & 94 & 26 & & & & \\
\hline Location & & & 2.018 & 0.569 & & \\
\hline Right colon & 58 & 11 & & & & \\
\hline Left colon & 61 & 17 & & & & \\
\hline Rectal & 16 & 5 & & & & \\
\hline Multiple & 6 & 2 & & & & \\
\hline Pathological classification & & & 19.274 & $<0.001$ & $1.345(0.865-2.090)$ & 0.188 \\
\hline Adenocarcinoma & 105 & 24 & & & & \\
\hline Partial mucinous & 16 & 0 & & & & \\
\hline Mucinous adenocarcinoma & 20 & 11 & & & & \\
\hline Differentiation grade & & & 7.260 & 0.027 & $0.761(0.343-1.689)$ & 0.502 \\
\hline Well & 2 & 0 & & & & \\
\hline Moderately & 84 & 15 & & & & \\
\hline Poorly & 55 & 20 & & & & \\
\hline Cancerous node & & & 12.595 & $<0.001$ & $3.011(1.067-8.498)$ & 0.037 \\
\hline Occurrence & 9 & 6 & & & & \\
\hline Absence & 132 & 29 & & & & \\
\hline Vascular invasion & & & 43.571 & $<0.001$ & $0.236(0.109-0.512)$ & $<0.001$ \\
\hline Occurrence & 29 & 21 & & & & \\
\hline Absence & 112 & 14 & & & & \\
\hline Perineural invasion & & & 13.654 & $<0.001$ & 1.552(0.679-3.546) & 0.297 \\
\hline Occurrence & 21 & 15 & & & & \\
\hline Absence & 120 & 20 & & & & \\
\hline TNM stage & & & 52.055 & $<0.001$ & $2.841(1.619-4.986)$ & $<0.001$ \\
\hline । & 40 & 1 & & & & \\
\hline$\|$ & 47 & 8 & & & & \\
\hline III & 46 & 19 & & & & \\
\hline IV & 8 & 7 & & & & \\
\hline KRAS & & & 0.007 & 0.934 & & \\
\hline Wild type & 71 & 16 & & & & \\
\hline Variant type & 70 & 19 & & & & \\
\hline NRAS & & & 0.368 & 0.544 & & \\
\hline
\end{tabular}


Table 4 Factors associated with recurrence free survival in the patients of LS and SCRC group (univariate and multivariate analysis) (Continued)

\begin{tabular}{|c|c|c|c|c|c|c|}
\hline \multirow{2}{*}{$\begin{array}{l}\text { Variable } \\
\text { Total }\end{array}$} & \multirow{2}{*}{$\begin{array}{l}\text { N. patients } \\
141\end{array}$} & \multirow{2}{*}{$\begin{array}{l}\text { N. events }{ }^{a} \\
35\end{array}$} & \multicolumn{2}{|c|}{ Univariate analysis } & \multicolumn{2}{|l|}{ Multivariate analysis } \\
\hline & & & $\overline{x^{2}}$ & $p$ value & Risk ratio $(95 \% \mathrm{Cl})$ & $p$ value \\
\hline Wild type & 136 & 33 & & & & \\
\hline Variant type & 5 & 2 & & & & \\
\hline
\end{tabular}

CEA Carcinoembryonic antigen, LS Lynch syndrome, SCRC Sporadic colorectal cancer, N. Number, Cl Confidence interval, CRC Colorectal cancer

${ }^{a}$ Events refers to tumor recurrence of primary CRC

DNA damage [7]. Several prospective-retrospective analyses demonstrated that adjuvant 5- fluorouracil based chemotherapy was effective in stage II and III CRC displaying MSI $[26,27,29]$. In our study, all patients who developed recurrence received 5 -fluorouracil based combined chemotherapy. Subgroup analysis of these patients show that the LS group had longer OS than the SCRC group. This result may indicate that for LS patients who developed recurrence, combined chemotherapy is effective for recurrent LS patients. In recent years, immune checkpoint modulators that directly target the exhaustion-related molecules PD-1/PD-L1 have proven to be effective specifically in tumors displaying the MSI phenotype with an objective response rate of approximately $40 \%$ [30]. Thus, immunotherapy or immunotherapy combined with chemotherapy can be another important treatment option in future practice.

During the analysis of prognostic factors in long-term survival, we found that microvascular invasion, cancer nodule occurrence, and the late TNM staging of the first primary CRC were independent risk factors that affect both RFS and OS. These factors have already been widely recognized as adverse prognostic factors [31, 32]. Thus, once an LS patient is identified, the affected relatives should undergo genetic counseling and standardized follow-up monitoring. Diagnosis at earlier stage and timely treatment can mitigate these adverse factors and ensure better survival prognoses.

Lastly, since early-onset CRC is another important characteristic of LS, we conducted a subgroup analysis and comparison of LS and SCRC early-onset CRC patients. However, we found no significant difference in comparison of OS, which indicates that early-onset CRC is an indicator of hereditary CRC in general. Notably, the incidence of early-onset CRC is increasing worldwide [33-35] which indicates that earlyonset CRC is a growing concern. Thus, early-onset cancer patients are recommended to undergo genetic testing to screen for LS.

The current study has the following limitations. Firstly, even though propensity score matching was used, selection bias of this retrospective study is still hard to avoid, which may bias the results. Secondly, the LS group contains patients with synchronous primary tumors, a factor which could not be balanced on the baseline and thus may affect the results. Lastly, the sample size for the LS group is relatively small, and would ideally require further accumulation and longer follow-up times.

\section{Conclusion}

The results of the current study indicate that LS patients have better long-term OS than SCRC patients, even
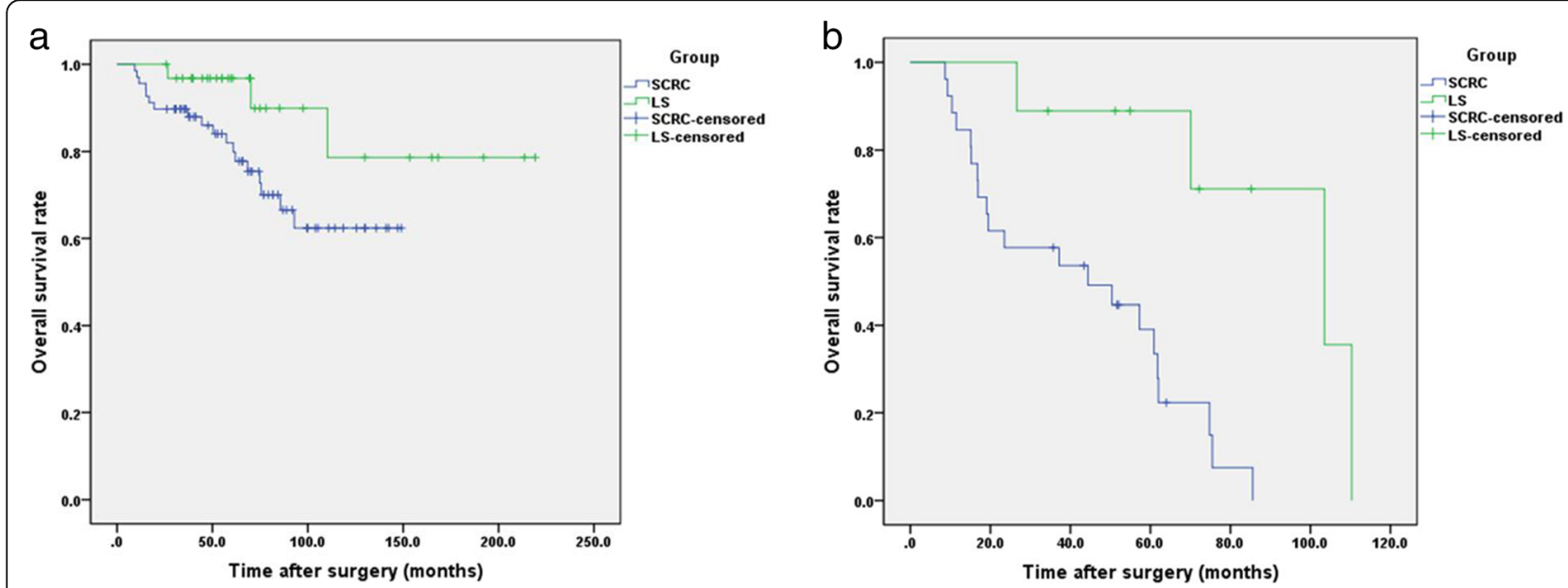

Fig. 3 Overall survival curves for patients in subgroup of LS group and SCRC group. Survivals were evaluated using Kaplan-Meier curves and compared with the log-rank test. a Early onset CRC patients; $\mathbf{b}$ CRC patients who developed tumor recurrence 
though the two groups have comparable RFS. In treating LS, especially for LS patients who developed recurrence of primary CRC, the combined chemotherapy may be the standard treatment. In addition, standardized postoperative monitoring for LS patients enabled us to detect metachronous tumors at earlier stages, which was a guarantee of a favorable prognosis. Lastly, establishing a database for LS patients across Asian populations would allow a deeper understanding of the clinicopathological, molecular-pathological and familial characteristics of LS in Asia, and would provide a stronger theoretical basis for the screening, treatment, and follow-up monitoring of these LS patients and their relatives.

\section{Abbreviations}

CRC: Colorectal cancer; CEA: Carcinoembryonic antigen; Cl: Confidence interval; IHC: Immunohistochemistry; LS: Lynch syndrome; MMR: Mismatch repair; MSI: Microsatellite instability; OS: Overall survival; RFS: Recurrence free survival; PSM: Propensity score matching; PV: Pathogenic variant; TFS: Tumor free survival; SCRC: Sporadic colorectal cancer

\section{Acknowledgments}

Not applicable.

\section{Authors' contributions}

(I) Conception and design: YX, FQL, and YX; (II) Administrative support: YX FQL, and $Y X$; (III) Provision of study materials or patients: $Y X, C L, C Z L$, and YQZ; (IV) Collection and assembly of data: YX, CL, TAG, and FQL; (V) Data analysis and interpretation: YX and TAG; (VI) Manuscript writing: YX; (VII) Final approval of manuscript: All authors.

\section{Funding}

Funding for this study was provided by the National Natural Science Foundation of China (No. 81472620), and the Shanghai Natural Science Foundation (No. 16ZR1406700). These funding bodies played no role in the design of the study andcollection, analysis, and interpretation of data and in writing the manuscript.

\section{Availability of data and materials}

The datasets used and/or analyzed during the current study are available from the corresponding authors on reasonable request.

\section{Ethics approval and consent to participate}

All examinations and treatments were conducted at the Fudan University Shanghai Cancer Center (Shanghai, China) and were in accordance with the Declaration of Helsinki. This study was approved by the Ethics Committee of the Fudan University Shanghai Cancer Center. Written informed consent was obtained from the individuals for the publication of any potentially identifiable images or data included in this article.

\section{Consent for publication}

All authors approved the final version of the manuscript.

\section{Competing interests}

The authors declare that they have no competing interests.

\section{Author details}

'Department of Colorectal Surgery, Fudan University Shanghai Cance Center, No. 270 Dong-An Road, Shanghai 200032, China. ${ }^{2}$ Department of Oncology, Shanghai Medical College, Fudan University, Shanghai 200032, China. ${ }^{3}$ Mechanical and Aerospace Engineering, University of California, 7400 Boelter Hall, Los Angeles, CA 90095, USA.
Received: 9 November 2020 Accepted: 26 December 2020

Published online: 09 January 2021

\section{References}

1. Bray F, Ferlay J, Soerjomataram I, Siegel RL, Torre LA, Jemal A. Global cancer statistics 2018: GLOBOCAN estimates of incidence and mortality worldwide for 36 cancers in 185 countries. CA Cancer J Clin 2018:68:394-424.

2. Guinney J, Dienstmann R, Wang X, de Reyniès A, Schlicker A, Soneson C, et al. The consensus molecular subtypes of colorectal cancer. Nat Med. 2015;21:1350-6.

3. Grady WM, Carethers JM. Genomic and epigenetic instability in colorectal cancer pathogenesis. Gastroenterology. 2008;135:1079-99.

4. Alex AK, Siqueira S, Coudry R, Santos J, Alves M, Hoff PM, et al. Response to chemotherapy and prognosis in metastatic colorectal Cancer with DNA deficient mismatch repair. Clin Colorectal Cancer. 2017;16:228-39.

5. Hampel H, Frankel WL, Martin E, Arnold M, Khanduja K, Kuebler P, et al. Screening for the Lynch syndrome (hereditary nonpolyposis colorectal cancer). N Engl J Med. 2005;352:1851-60.

6. Lynch HT, Snyder CL, Shaw TG, Heinen CD, Hitchins MP. Milestones of Lynch syndrome: 1895-2015. Nat Rev Cancer. 2015:15:181-94.

7. Gryfe R, Kim H, Hsieh ET, Aronson MD, Holowaty EJ, Bull SB, et al. Tumor microsatellite instability and clinical outcome in young patients with colorectal cancer. N Engl J Med. 2000;342:69-77

8. Koopman M, Kortman GA, Mekenkamp L, Ligtenberg MJ, Hoogerbrugge N, Antonini NF, et al. Deficient mismatch repair system in patients with sporadic advanced colorectal cancer. Br J Cancer. 2009;100:266-73.

9. Popat S, Hubner R, Houlston RS. Systematic review of microsatellite instability and colorectal cancer prognosis. J Clin Oncol. 2005;23:609-18.

10. Ribic CM, Sargent DJ, Moore MJ, Thibodeau SN, French AJ, Goldberg RM, et al. Tumor microsatellite-instability status as a predictor of benefit from fluorouracil-based adjuvant chemotherapy for colon cancer. N Engl J Med. 2003;349:247-57.

11. Cohen R, Buhard O, Cervera P, Hain E, Dumont S, Bardier A, et al. Clinical and molecular characterisation of hereditary and sporadic metastatic colorectal cancers harbouring microsatellite instability/DNA mismatch repair deficiency. Eur J Cancer. 2017;86:266-74

12. Lautrup CK, Mikkelsen EM, Lash TL, Katballe N, Sunde L. Survival in familial colorectal cancer: a Danish cohort study. Familial Cancer. 2015;14:553-9.

13. Møller P, Seppälä T, Bernstein I, Holinski-Feder E, Sala P, Evans DG, et al. Cancer incidence and survival in Lynch syndrome patients receiving colonoscopic and gynaecological surveillance: first report from the prospective Lynch syndrome database. Gut. 2017;66:464-72.

14. Møller P, Seppälä T, Bernstein I, Holinski-Feder E, Sala P, Evans DG, et al. Incidence of and survival after subsequent cancers in carriers of pathogenic MMR variants with previous cancer: a report from the prospective Lynch syndrome database. Gut. 2017;66:1657-64.

15. Dominguez-Valentin M, Seppälä TT, Sampson JR, Macrae F, Winship I, Evans DG, et al. Survival by colon cancer stage and screening interval in Lynch syndrome: a prospective Lynch syndrome database report. Hered Cancer Clin Pract. 2019:17:28.

16. Liu GC, Liu RY, Yan JP, An X, Jiang W, Ling YH, et al. The heterogeneity between Lynch-associated and sporadic MMR deficiency in colorectal cancers. J Natl Cancer Inst. 2018:110:975-84.

17. Haraldsdottir S, Hampel H, Wu C, Weng DY, Shields PG, Frankel WL, et al. Patients with colorectal cancer associated with Lynch syndrome and MLH1 promoter hypermethylation have similar prognoses. Genet Med. 2016;18: 863-8.

18. Vasen HF, Watson P, Mecklin JP, Lynch HT. New clinical criteria for hereditary nonpolyposis colorectal cancer (HNPCC, Lynch syndrome) proposed by the international collaborative group on HNPCC. Gastroenterology. 1999:116:1453-6.

19. Umar A, Boland CR, Terdiman JP, Syngal S, De La Chapelle A, Rüschoff J, et al. Revised Bethesda guidelines for hereditary nonpolyposis colorectal cancer (Lynch syndrome) and microsatellite instability. J Natl Cancer Inst. 2004;96:261-8.

20. Guo TA, Wu YC, Tan C, Jin YT, Sheng WQ, Cai SJ, et al. Clinicopathologic features and prognostic value of KRAS, NRAS and BRAF mutations and DNA mismatch repair status: a single-center retrospective study of 1,834 Chinese patients with stage I-IV colorectal cancer. Int J Cancer. 2019;145:1625-34.

21. Richards S, Aziz N, Bale S, Bick D, Das S, Gastier-Foster J, et al. Standards and guidelines for the interpretation of sequence variants: a joint consensus 
recommendation of the American College of Medical Genetics and Genomics and the Association for Molecular Pathology. Genet Med. 2015; 17:405-24.

22. Gupta S, Provenzale D, Llor X, Halverson AL, Grady W, Chung DC, et al. NCCN guidelines insights: genetic/familial high-risk assessment: colorectal, version 2.2019. J Natl Compr Cancer Netw. 2019;17:1032-41.

23. Moertel CG. Multiple primary malignant neoplasms: historical perspectives Cancer. 1977;40:1786-92

24. Koh PK, Kalady M, Skacel M, Fay S, McGannon E, Shenal J, et al. Familial colorectal cancer type $\mathrm{X}$ : polyp burden and cancer risk stratification via a family history score. ANZ J Surg. 2011;81:537-42.

25. Klarskov L, Holck S, Bernstein I, Nilbert M. Hereditary colorectal cancer diagnostics: morphological features of familial colorectal cancer type $\mathrm{X}$ versus Lynch syndrome. J Clin Pathol. 2012;65:352-6.

26. Sinicrope FA, Foster NR, Thibodeau SN, Marsoni S, Monges G, Labianca R, et al. DNA mismatch repair status and colon cancer recurrence and survival in clinical trials of 5-fluorouracil-based adjuvant therapy. J Natl Cancer Inst. 2011;103:863-75.

27. Hemminki $A$, Mecklin JP, Järvinen $H$, Aaltonen LA, Joensuu H. Microsatellite instability is a favorable prognostic indicator in patients with colorectal cancer receiving chemotherapy. Gastroenterology. 2000;119:921-8.

28. Renkonen-Sinisalo L, Seppälä TT, Järvinen HJ, Mecklin JP. Subtotal colectomy for Colon Cancer reduces the need for subsequent surgery in Lynch syndrome. Dis Colon Rectum. 2017;60:792-9.

29. Sargent DJ, Marsoni S, Monges G, Thibodeau SN, Labianca R, Hamilton SR, et al. Defective mismatch repair as a predictive marker for lack of efficacy of fluorouracil-based adjuvant therapy in colon cancer. J Clin Oncol. 2010;28: 3219-26.

30. Le DT, Uram JN, Wang H, Bartlett BR, Kemberling H, Eyring AD, et al. PD-1 blockade in tumors with mismatch-repair deficiency. N Engl J Med. 2015; 372:2509-20.

31. Dienstmann R, Villacampa G, Sveen A, Mason MJ, Niedzwiecki D, Nesbakken A, et al. Relative contribution of clinicopathological variables, genomic markers, transcriptomic subtyping and microenvironment features for outcome prediction in stage II/III colorectal cancer. Ann Oncol. 2019;30: $1622-9$.

32. Roxburgh CS, McMillan DC, Richards $\mathrm{CH}$, Atwan M, Anderson JH, Harvey $\mathrm{T}$, et al. The clinical utility of the combination of $\mathrm{T}$ stage and venous invasion to predict survival in patients undergoing surgery for colorectal cancer. Ann Surg. 2014;259:1156-65.

33. Chen W, Zheng R, Baade PD, Zhang S, Zeng H, Bray F, et al. Cancer statistics in China, 2015. CA Cancer J Clin. 2016;66:115-32.

34. Siegel RL, Torre LA, Soerjomataram I, Hayes RB, Bray F, Weber TK, Jemal A. Global patterns and trends in colorectal cancer incidence in young adults. Gut. 2019;68:2179-85.

35. Vuik FE, Nieuwenburg SA, Bardou M, Lansdorp-Vogelaar I, Dinis-Ribeiro M, Bento $\mathrm{MJ}$, et al. Increasing incidence of colorectal cancer in young adults in Europe over the last 25 years. Gut. 2019;68:1820-6.

\section{Publisher's Note}

Springer Nature remains neutral with regard to jurisdictional claims in published maps and institutional affiliations.

Ready to submit your research? Choose BMC and benefit from:

- fast, convenient online submission

- thorough peer review by experienced researchers in your field

- rapid publication on acceptance

- support for research data, including large and complex data types

- gold Open Access which fosters wider collaboration and increased citations

- maximum visibility for your research: over $100 \mathrm{M}$ website views per year

At BMC, research is always in progress.

Learn more biomedcentral.com/submissions 